International Journal of Current Advanced Research

ISSN: O: 2319-6475, ISSN: P: 2319 - 6505, Impact Factor: SJIF: 5.995

Available Online at www.journalijcar.org

Volume 6; Issue 3; March 2017; Page No. 2741-2744

DOI: http://dx.doi.org/10.24327/ijcar.2017.2744.0094

Research Article

\title{
RELATIONSHIP BETWEEN NURSE TO PATIENT RATIO AND NURSES' SATISFACTION AMONG REGISTERED NURSES WORKING IN A SELECTED PRIVATE HOSPITAL, MALAYSIA
}

\author{
*Mini Rani Mary Beth ${ }^{1}$ and Suzisurainie Binti Yaacob²
}

\author{
Division of Nursing, International Medical University,126, JalanJalil Perkasa 19, Bukit Jalil, \\ 57000, Kuala Lumpur, Malaysia
}

\section{A R T I C L E I N F O \\ Article History: \\ Received $8^{\text {th }}$ December, 2016 \\ Received in revised form $19^{\text {th }}$ January, 2017 \\ Accepted $12^{\text {th }}$ February, 2017 \\ Published online $28^{\text {th }}$ March, 2017}

\section{Key words:}

Nurse to patient ratio,

satisfaction, registered nurses

\begin{abstract}
A B S T R A C T
Background: Job satisfaction among nurses has been identified as the main factor that contributes to nursing shortage. Adequate nurse to patient ratios are important and is a key for nurse job satisfaction.Objective: The objective of this study is to assess the relationship between nurse to patient ratio and nurse's satisfaction using self-developed questionnaire. Methods and materials: Data was collected from88 registered nurses who were working in Medical Surgical wards of a selected private hospital in Melaka, Malaysia.Random sampling technique was used to select samples. Data were analysed using SPSS version 22. Results: The registered nurses rated high for the statement 'staff under stress cannot perform their job satisfactorily'. Besidesthat, a majority of nurses are highly satisfied with working in team and Continuous professional development and trainings. However, the registered nurses were least satisfied with the staff patient ratio in their unit and the nursing staffing. There is a significant relationship between nurse to patient ratio and nurses' satisfactionwith the value of $\mathrm{p}<0.05$. Conclusion: The hospital management should ensure to maintain adequate nursing staffing in order to provide a positive and healthy workplace environment that can contribute to nurses' satisfaction.
\end{abstract}

Copyright@2017 Mini Rani Mary et al. This is an open access article distributed under the Creative Commons Attribution License, which permits unrestricted use, distribution, and reproduction in any medium, provided the original work is properly cited.

\section{INTRODUCTION}

Nurses' job satisfaction is an important issue because it has a big impact on the quality of the nursing profession. Nurses must be free from burnout and must be satisfied in their profession to be more productive, creative and committed.[1] Adequate staffing levels are essential for staff nurse job satisfaction.[2] It has also been reported that nurse job satisfaction is closely related to working conditions and the organizational environment, job stress, role conflict and ambiguity.[3]'Nurses in hospitals with higher patient-to-nurse ratios were to exhibit burnout scores above published norms and to be dissatisfied with their jobs.[4] Nurse patient ratio was identified as a one of the stress factors by the nurses.[5] According to World Health Statistic (2014), in Malaysia, Nurse to patient ratio is higher with approximate density of 32.8 nurses per 10000 population while in nearest country Singapore the ratio density is 63.9 nurses per 10000 population ( World Health Organisation, 2014). Based on the report from Health Human resources, Ministry of Health Malaysia in 2013, nurse's ratio to population is 1: 333. [6].

*Corresponding author: Mini Rani Mary

Division of Nursing, International Medical University,126, JalanJalil Perkasa 19, Bukit Jalil, 57000, Kuala Lumpur, Malaysia
By the year 2020, the total number of nurses is targeted to reach approximately 174,400 with the nurse to patient ratio to be 1:200 [7]. The high patient to nurse ratio could be due to the current nursing shortage. It is also reported that unbalanced nurse to patient ratio which decreased their relationship with patients and the opportunity to use knowledge and skills effectively and effect nurse's satisfaction. [8] The maximum nurse to patient ratio is 1:4.1:6 and 1:10 for the day shift, evening and night shift are standardized for all the general nursing wards. [9] This was supported by (Patterson J. 2011) who stated that optimal nurse to patient ratio 1:4 will provide the best patient outcomes [10].

In this study, the Herzberg's two factor theory of job satisfaction was used as the theoretical framework. The two set of factors in this theory that influence motivation in the workplace are hygiene factors and motivator factors. These two factors are important to provide and give impact for employee's satisfaction in work environment. [11]

\section{Objective}

The objective of the study is to determine the relationship between nurse patient ratio and nurse satisfaction among registered nurse working in the medical and surgical wards a selected private hospital in Malaysia. 


\section{METHODS AND MATERIALS}

A quantitative, correlational, non-experimental design was used in this study to determine the relationship between nurse to patient ratio and nurses' satisfaction. The target population were registered nurses working in medical and surgical wards in one of the private hospital in Malaysia.

This study used the random sampling. Sample size was calculated using Raosoft software based on formula $5 \%$ margin error and $95 \%$ of confidence level and a $50 \%$ of response rate. A total of 88 registered nurses participated in the study.

\section{Inclusion criteria}

- Registered nurses currently employed as a staff in the hospital during the study.

- Nurses who are willing to participate in this study.

- Must be able to read and understand English or Bahasa

- Registered nurses working in medical and surgical wards

\section{Exclusion criteria}

The nurse manager / supervisor, clinical instructor and nonnursing personal (ward assistant, nursing aids)

The instrument for this study is a self-developed questionnaire which is developed through comprehensive literature review. Section A consists of demographic profile of the participants includes age, gender, marital of status, number of years of experience in nursing, highest level of nursing education and current nurse to patient ratio in the unit.

Section B consists of 21 questions and is related to the study of nurses' perceptions regarding nurse to patient ratio in the units. The questionnaire is based on a 5 point Likert scale scoring from 1: strongly disagree to 5: strongly agree.

Section C of the questionnaire is related to nurses' satisfaction towards nurse patient ratio. It comprises 10 questions and the scale ranging from 1: unsure to 5: highly satisfied.

A pilot study was conducted to determine the reliability of the questionnaire. The Cronbach Alpha coefficient for the questionnaire was 0.825 .
Validity of the questionnaire was done by the panel of experts in the hospital.

The research was approved by the International Medical University (IMU) Joint Committee of the Research and Ethical Committee. Written permission was obtained from the CEO and nursing director of the hospital to conduct the study. Written consents were obtained from all participants. Participants' rights to privacy, autonomy, confidentiality, fair treatment, protection from discomfort and harm were well preserved.

Data was analysed by Statistical Package for Social Science Software (SPSS) version 22. Descriptive statistics was used to analyse the demographic data of the participants and presented via frequency, percentage, mean and standard deviation. Pearson correlation test was used to analyse the relationship between nurse to patient ratio and nurse's satisfaction.

\section{RESULTS}

The results of the demographic data shows that a majority of the nurses $39(44.3 \%)$ belonged to the age group between 2025 years and $87(98.9 \%)$ of them were females. There were 50 $(56.8 \%)$ who were single and $38(43.2 \%)$ of them married. The results of the numberof years of working experience shows that $53(60 \%)$ of them had 0-3 years of experience, followed by $20(23 \%)$ with $4-6$ years of experience and 15 $(17 \%)$ with 7 years and above. A majority of respondents hold diploma in Nursing 74 (84\%), while 10 (11\%) had post basic and only $4(5 \%)$ had bachelor degree in nursing.

The current nurse to patient ratio shows that $48(54.5 \%)$ of the registered nurses working in medical and surgical ward provided care for 9 patients and above in one shift, whereas $20(22.7 \%)$ cared for 4-6 patients, $18(20.5 \%)$ cared for 7-9 patients and $2(2.3 \%)$ cared for 1-3 patients.

Table 1 shows the nurses perceptions regarding nurse to patient ratio. The participants rated the statement "Staff who are under stressed cannot perform their job satisfactorily " higher followed by "Increased nursing staff levels would do the most to improve job satisfaction".

Table 1 Nurses' perceptions regarding nurse to patient ratio in the units $(n=88)$

\begin{tabular}{|c|c|c|}
\hline Nurses' perceptions regarding nurse to patient ratio in the units & Mean (M) & SD \\
\hline Staff under stress cannot perform their job satisfactorily & 4.38 & 0.649 \\
\hline Increased nursing staff levels would do the most to improve job Satisfaction & 4.36 & 0.664 \\
\hline Patients and nurse are at risk of harm if a nurse has to care for more than eight people in my unit during the day & 4.24 & 0.695 \\
\hline Nursing staffing will have an effect on nurse to patient ratios in my unit & 4.17 & 0.776 \\
\hline Minimum ratio would reduce the stress on all staff in my units & 4.10 & 0.695 \\
\hline Low nurse to patient ratios affects my job satisfaction & 4.08 & 0.834 \\
\hline Safe nurse to patient ratios improve quality of nursing service, nurse recruitment and nurse retention & 4.07 & 0.675 \\
\hline Safe nurse to patient ratio will boost self-esteem and increase nurses' satisfaction & 4.05 & 0.693 \\
\hline In my opinion, minimum ratios should be addressed in law, made clear and widely implemented & 4.05 & 0.726 \\
\hline Nurse to patient ratio reflect my time spent with patients or on clinical tasks & 3.91 & 0.737 \\
\hline Higher average nurse to patient ratios in my unit strongly effects my job satisfaction & 3.86 & 0.805 \\
\hline Amount of workload reduces with minimum nurse to patient ratios & 3.66 & 0.981 \\
\hline The number of patient has been assigned resulted in nurses satisfaction in my unit & 3.64 & 0.833 \\
\hline I understand with the current practice (nurse to patient ratio) in my unit & 3.47 & 0.909 \\
\hline Nurse to patient ratio are fixed in my unit & 3.28 & 0.946 \\
\hline Nursing staffing per shift in my unit is acceptable to practice safe nurse to patient ratios & 3.26 & 0.928 \\
\hline I have opportunity to work independently with current nurse to patient ratios practice in my unit & 3.13 & 0.945 \\
\hline I have an adequate amount of time to spend with each patient & 3.05 & 1.071 \\
\hline Nurse to patient ratios are safe in my unit & 3.02 & 0.947 \\
\hline Number of patients assigned to me is reliable & 2.97 & 0.976 \\
\hline I have enough time to provide direct patient care in my unit with current nurse to patient ratios & 2.82 & 1.056 \\
\hline
\end{tabular}


Table 2 shows the results of the nurses satisfaction towards nurse to patient ratio. Nurses ratedhigh for the statement "Working in team" and "Continuous professional development and trainings".". From the table, it is seen that the least domian chosen by nurses were "Staff patient ratio in the unit" and "adequate staffing".

Table 2 Nurse's satisfaction towards nurse to patient ratio in the units $(\mathrm{n}=88)$

\begin{tabular}{ccc}
\hline $\begin{array}{c}\text { Nurse's satisfaction towards nurse to } \\
\text { patient ratio in the units }\end{array}$ & $\begin{array}{c}\text { Mean } \\
(\boldsymbol{M})\end{array}$ & $\begin{array}{c}\text { Standard } \\
\text { deviation } \\
(\boldsymbol{S} \boldsymbol{D})\end{array}$ \\
\hline $\begin{array}{c}\text { Working in team } \\
\text { Continuous professional development and } \\
\text { trainings }\end{array}$ & 4.06 & .717 \\
Achievement & 4.01 & .634 \\
Recognition for a job well done & 3.81 & .522 \\
Work responsibility and role expectations & 3.81 & .641 \\
Work environment satisfaction & 3.76 & .643 \\
Organization policy on staff patient ratio & 3.70 & .730 \\
The workload of my current job /overtime & 3.58 & .827 \\
Staff patient ratio in the unit & 3.38 & .875 \\
Adequate staffing & 3.28 & .843 \\
\hline
\end{tabular}

Note *score ranged from 1 (unsure) to 5 (highly satisfied)

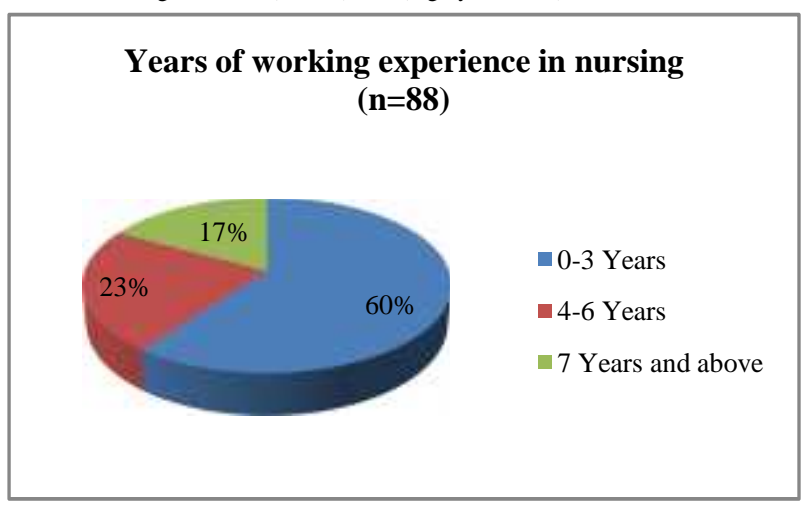

Figure 1 Years of working experience in nursing of participants.

Highest level of Nursing education $(n=88)$

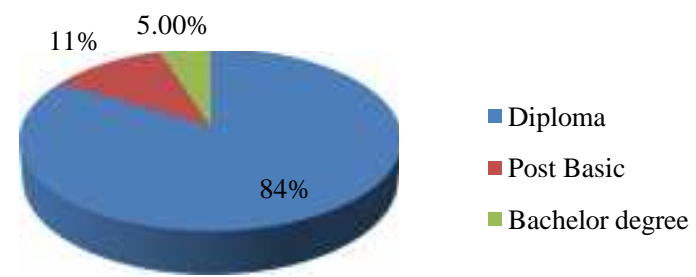

Figure 2 Highest level of nursing education of participants.

In addition, Pearson correlation test was used to determine the relationship between nurse to patient ratio and nurses' satisfaction and the result shows that there is significant relationship between nurses to patient ratio with the nurses' satisfaction with the value of $\mathrm{p}<0.05$.

\section{DISCUSSION}

The findings of this study indicate the need for taking necessary actions to improve nurse's satisfaction and needs. Nurses are responsible for direct patient care and for the improvement of patient outcomes. A study conducted by Kalisch B and Lee K.H ( 2014) shows that adequate staffing level are required to maintain nurses satisfaction. Nurses also have to take the responsibility to improve the quality and services of the healthcare organization. Hence, the importance of adequate staffing to maintain safe nurse to patient ratio and increase the nurses' satisfaction. Nurses' satisfaction is important because it can influence the patient outcomes.[2] This finding is also supported by Atefi et al (2014) that unbalanced nurse to patient ratio which decreased their relationship with patients and the opportunity to use knowledge and skills effectively and effect nurse's satisfaction.[8]

A research conducted by Lee Cheng Poh (2008) on nurse's job satisfaction in a private hospital Malaysia concluded that two factors of job satisfaction for nurses in the private hospitals in Malaysia are professional status and autonomy. Jung I.C. et al (2015) reported that job satisfaction was most influenced by burnout, followed by job stress and mindfulness and it give negative impact on job satisfaction.[12] However, Arbabisarjau et al (2013) surveyed 491 registered nurses in Iran and found a negative correlation between job stress and performance.[13]

\section{CONCLUSION}

The findings of this study revealed that there is a significant relationship between nurse to patient and nurses' satisfaction among registered nurses working in medical and surgical wards of a selected private hospital in Malaysia. Therefore, it is essential that the hospital management should do the necessary actions in order to improve the nurse's satisfaction as well as nursing services. In addition, the hospital management should ensure adequate staffing in order to provide a positive and healthy workplace environment that can contribute to nurses' satisfaction. Nurse's satisfaction has been indicated as an important factor that lead to nurse's job outcomes. It gives impact upon the quality of nursing services. Most of the study from various countries also identified that work outcomes and environment can affects overall nurse's satisfaction.

\section{Acknowledgement}

The researchers express their deepest gratitude to the Head of Nursing Division, International Medical University (IMU), Associate Dean of IMU Research Laboratory, and Deputy CoChairman, IMU Joint-Committee on Research and Ethics for reviewing the research proposal and approving the research fund. The researchers are deeply indebted to the hospital CEO and directors for granting permission to conduct pilot study and data collection, respectively.

\section{References}

1. Annick Willem, Marc Buelens, Ives De Jonghe. (2007). Impact of organizational structure on nurses' job satisfaction: A questionnaire survey. International Journal of Nursing Studies 44: 1011-1020.

2. Kalisch B., \& Lee K.H. (2014). Staffing and job satisfaction: nurses and nursing assistants. Journal of Nursing Management.22; 465-471.

3. Lu H., et. al. (2012). Job satisfaction among hospital nurses revisited: A systematic review.International Journal of Nursing Studies, 49, 1017-1038.

4. Aiken et.al. (2002) Hospital nurse staffing and patient mortality, nurse burnout, and job satisfaction. JAMA 288 (16), 1987-1993. 
5. Raja Lexshimi R.G, Saadia Tahir, Santhna L.P, Md Nizam J. (2007). Prevalence of Stress and Coping Mechanism among Staff Nurses in the Intensive Care Unit Med \& Health 2007; 2(2): 146-153.

6. Ministry of health. (2013). Annual report: Kuala Lumpur. Retrieved from http://www.moh.gov.my/ index.php/pages/view/321

7. Barnett, T., Namasivayam. P., \& Narudin, D.A.A. (2010).A critical review of the nursing shortage in Malaysia.International Nursing Review, 57, 32-39.

8. Atefi N., et.al. (2014) Factors influencing registered nurses perception of their overall job satisfaction: a qualitative study. International Nursing Review 61,352-360.
9. Oostrveen C.J., et. al. (2015). Nurse staffing issues are just the tip of the iceberg: A qualitative study about nurses' perceptions of nursing staffing. International Journal of Nursing Studies. 52; 1300-1309.

10. Patterson J. (2011). The effects of nurse to patient ratios.Nursing Times .107, 22-25.

11. Tang Wai Mun \& Muhammad FaizalA. Ghani (2012). Job Satisfaction among the Nurse Educators in the Klang Valley, Malaysia. International Journal of Nursing Science, 2(4): 29-33.

12. Jung Im Choi \& Myung Suk Koh (2015). Relations of Job Stress, Burnout, Mindfulness and Job Satisfaction of Clinical Nurses. International Journal of BioScience and Bio-Technology, 7(3), 121-128.

13. Arbabisarjou A. et. al. (2013).The relationship between job stress and performance among the hospitals nurses. World of Sciences Journal, (2).

\section{Please cite this article in press as:}

Mini Rani Mary Beth and Suzisurainie Binti Yaacob (2017), Relationship between nurse to patient ratio and nurses' satisfaction among registered nurses working in a selected private hospital, Malaysia, International Journal of Current Advanced Research, 6(3), pp. 2741-2744.

http://dx.doi.org/10.24327/ijcar.2017. 2744.0094 